\title{
Planejamento territorial e análise do potencial geoturístico no município de Morros (MA): dinâmica dos conceitos de Ecoturismo, Geoturismo e Sustentabilidade Ambiental
}

\author{
Territorial planning and analysis of geotourism potential in the \\ municipality of Morros (MA, Brazil): dynamics of the concepts of \\ Ecotourism, Geotourism and Environmental Sustainability
}

\author{
Gabriel Macedo Monteiro, Saulo Ribeiro dos Santos
}

\begin{abstract}
RESUMO: O objetivo do presente artigo é analisar a relação dialética existente entre a ciência geográfica, por meio dos preceitos fundamentais da categoria território, com os processos de desenvolvimento da prática do turismo sustentável através do Ecoturismo e Geoturismo de caráter conservacionista no município de Morros no Maranhão, que contemple as dimensões do planejamento estratégico da atividade turística a curto, médio e/ou longo prazo. Além disso, o trabalho busca a interpretação do território, seus potenciais turísticos, naturais e o fomento à implantação de uma efetiva qualidade na implantação da educação ambiental local e dos visitantes. Para tanto, utilizou-se do método qualitativo e as técnicas de pesquisa bibliográfica e documental. Nesse sentido, são evidenciados, de maneira geral, os potenciais turísticos do município de morros, oriundos da dinâmica resultante entre as relações sociais, econômicas e naturais de caráter extraordinário, assim como a busca pelo fomento de questões acerca da conservação de ambientes naturais e a possibilidade de implementar ações educativas em atividades que a priori propiciem o consumo desse território geográfico com base no planejamento público.
\end{abstract}

PALAVRAS CHAVE: Ecoturismo; Morros; Território; Planejamento; Maranhão.

ABSTRACT: The objective of this article is to analyze the dialectical relationship between geographic science, through the fundamental precepts of the territory category, with the processes of development of sustainable tourism practice through Ecotourism and Geotourism of conservation character in the municipality of Morros in Maranhão, which contemplates the dimensions of strategic planning of tourism activity in the short, medium and/or long term. In addition, the work seeks the interpretation of the territory, its tourist, natural potentials and the promotion of the implementation of an effective quality in the implementation of local environmental education and visitors. For this purpose, the qualitative method and the techniques of bibliographic and documentary research were used. In this sense, the tourist potentials of the municipality of Morros are evidenced, derived from the resulting dynamics between social, economic and natural relations of extraordinary character, as well as the search for the promotion of questions about the conservation of natural environments and the possibility of promoting educational actions in activities that a priori propitiate the consumption of this geographical territory based on public planning.

KEYWORDS: Ecotourism; Morros; Hills; Territory; Planning; Maranhão. 


\section{Introdução}

O crescente processo das práticas turísticas no Polo Munim e a demanda por insumos produtivos que visam suprir as atividades antrópicas no território sejam elas de caráter econômico ou para manutenção das populações, tem estimulado cada vez mais cenários e modelos do turismo de massa associados à exploração dos recursos naturais, sem que haja a necessária preocupação dos gestores públicos em integrar a sustentabilidade, a conservação do patrimônio ambiental e os atores sociais locais. Nesse sentido, a prática turística, nas últimas décadas, apresenta-se como uma das principais variáveis que, evidentemente, ocasionam rupturas no equilíbrio dos sistemas naturais e que, sobretudo, são contribuintes para os processos de degradação destes (LAMBIN; MEYFROIDT, 2010).

Compreender a relação entre a ciência da Geografia e as categorias Turismo, Espaço e, sobretudo, do respectivo Território, a partir das inúmeras relações e implicações existentes com os processos de planejamento e gestão dos destinos turísticos permite ao ser humano pensar sobre uma série de pares dialéticos e dialógicos (MORIN, 1999) que substanciam a prática do fenômeno turístico contemporâneo.

Mediante tais aspectos, objetiva-se no presente estudo analisar a relação dialética existente entre a ciência geográfica, por meio dos preceitos fundamentais da categoria território, com os processos de desenvolvimento da prática do turismo sustentável através do Ecoturismo e Geoturismo de caráter conservacionista no município de Morros no Maranhão, que contemple as dimensões do planejamento estratégico da atividade turística a curto, médio e/ou longo prazo.

Nesse sentido, a gestão pública local deverá sempre direcionar seus objetivos para o alcance do ordenamento territorial a partir da conjunção dialógica entre as ações dos diferenciados agentes sociais que participam do processo turístico, seja direta ou indiretamente. Ou seja, os órgãos competentes, na figura de seus gestores, devem perceber e atentar-se para cada detalhe/situação específica, absorvendo dados e mantendo-se receptivos às manifestações que contribuem para o desenvolvimento de alternativas palpáveis para o setor. Somente com tal experiência e conhecimentos será possível despertar, no turista, a "sensibilidade a fim de provocar-Ihe diferentes leituras" (CASTROGIOVANNI et al., 1999, p.25). Dessa forma, será possível fazer das potencialidades do município de Morros (MA), seja pela sua história ou belezas naturais, uma oportunidade de desenvolvimento local, além de fomentar atrativos que o tornem interessante sob a perspectiva dos visitantes e moradores.

\section{Planejamento Turístico: uma concepção de análise entre o Geoturismo e Território}

É inegável a atual percepção da ciência Geográfica como uma ciência social que possui em seu vasto e precioso arcabouço teórico um conjunto de subcampos (entendese: "Geografia Física" - Pedologia, Biogeografia, Climatologia, Hidrologia e a "Geografia Humana" - Urbana, Agrária, Cultural, Política, Econômica, Histórica e, mais recentemente, a perspectiva do Turismo, por exemplo) e categorias geográficas, como o território, que visam expressar a sua identidade e explicar da maneira mais satisfatória possível à realidade local/regional abordada, ao tentar compreender e discutir às diversas ações antropogênicas no ato de modificar a superfície terrestre ao longo dos períodos econômicos e históricos.

Nesse sentido, é plenamente possível a correlação direta entre o fenômeno do turismo com conceitos inerentes do saber geográfico, como natureza, paisagem, lugar e, 
como já aludido, o território. Essa análise sobre o papel do turismo na produção e configuração do território, encontra-se na perspectiva espacial e territorial do turismo, através de percepção integradoras e sistêmicas dos fenômenos físicos, sociais e econômicos. Algumas dessas observações recorrem à teoria das territorialidades, valendo-se de conceitos e sistemas territoriais para a construção de modelos de desenvolvimento territorial do turismo (SILVEIRA, 2002).

O turismo, portanto, apresenta-se como um fenômeno extremamente complexo e multidisciplinar, bem como a ciência geográfica, e por isso deve ser percebido e interpretado sob as mais diversas vertentes, sejam elas sociais, econômicas/financeiras, culturais, políticas e ambientais. A prática turística influencia todo um território, pois ao passo que permite a sua concretização é, também, modificado/construído por ela, por meio da dialética do processo de desterritorialização e reterritorialização, perpassando 0 conceito de multiterritorialidade, cuja fonte encontra-se em Haesbaert (HAESBAERT, 2004; 2005).

Assim, o território e a prática turística só poderão ser devidamente apreendidos pelos pesquisadores e aplicados pelos demais gestores competentes dentro de uma concepção integralista, ou seja, de multiterritorialidade. Esse entendimento do fenômeno da prática turística oferece preciosos subsídios para uma efetiva visualização dos processos de produção e organização do espaço maranhense, sobretudo do Polo Munim, por exemplo, assim como uma alusão precisa dos impactos econômicos, ambientais e sociais que possam ser oriundos da produção do território. De acordo com o exposto, Rodrigues (1996) explana:

O fenômeno do turismo, por sua natureza complexa [...], é um importante tema que deve ser tratado no âmbito de um quadro interativo de disciplinas de domínio conexo, em que o enfoque geográfico é de fundamental importância, uma vez que, por tradição, lida com a dualidade sociedade $x$ natureza. (RODRIGUES, 1996, p.22)

Isso significa que enquanto houver a interação das ações humana sobre o espaço e os elementos da natureza que o compõe, transformando-os e modificando-os ao longo do tempo, seja através das práticas turísticas, processos de uso e ocupação, trabalho e, posteriormente às ações, a atribuição de valor e importância ao espaço social e nas relações ali presentes, haverá a existência da categoria território. Assim, Raffestin (1993) ressalta que o elemento poder era um instrumento institucionalizado, tendo como limite espacial o território dos países, por exemplo.

Conforme Saquet (2007, p.127), "o processo de apropriação e produção do território depende da economia, política e cultura, que ocorrem concomitantemente. Ou seja, o território é resultado da união desses fatores, além das relações de poder e questões socioespaciais".

Diante disso, também afirma LIMA (2006, p. 17):

O controle e a apropriação do território podem ser evidenciados através das interferências no modo de vida da sociedade. [...] a inevitável substituição de valores, princípios, modos de vida, as inovações tecnológicas na vida das comunidades tradicionais recondicionam a relação das pessoas, constituindo novas perspectivas relacionais no/do território. 
Sob esse viés conceitual, Santos (1994) percebe o território como uma analogia entre formas e objetos, em uma análise de fluidez que controlam/guiam as relações econômicas atuais. É graças a isso, que estão presentes hoje no território, os chamados "novos recortes". Esses elementos seriam consequências da nova construção do espaço e do novo funcionamento do território, através daquilo que o autor denomina de horizontalidades e verticalidades.

As horizontalidades serão os domínios da contiguidade, daqueles lugares vizinhos reunidos por uma continuidade territorial, enquanto as verticalidades seriam formadas por pontos distantes uns dos outros, ligados por todas as formas e processos sociais (SANTOS, 1994, p. 16).

O turismo acontece no território, assim como geoturismo que está vinculado ao entendimento de geologia e geomorfologia local que permite ao turista melhor compreensão, indo além da apreciação estética. Ou seja, a perspectiva desse contexto espacial nos remete à noção do conceito de redes. O processo de rede é perceptível no geoturismo, pois, o visitante passa a compreender o local sob uma ótica educativocientífico de acordo com as experiências locais (NEWSOME; DOWNLING, 2018).

[...] é certo pontuar que o geoturismo configura-se como uma nova atividade turística, uma vez que apresenta aportes teórico-metodológicos, produtos e filosofias diferenciadas. [...] expõe que o geoturismo deve ser encarado enquanto um novo segmento por apresentar potencialidades, características e objetivos próprios ao buscar a interação entre a paisagem e os aspectos científicos e culturais, salientando elementos negligenciados no ecoturismo, como a geodiversidade (MEIRA; NASCIMENTO; SILVA, 2020, p. 06).

Esse conceito de território justifica a nova configuração da realidade justificando a verticalidade dos territórios, oriundos de lugares contínuos e de localidades dispostas em rede. A princípio, são os mesmos lugares e/ou pontos, entretanto, apresentando simultaneamente funcionalizações diferentes, podendo ainda, ser divergentes ou opostas.

Esse olhar holístico e sistêmico do geógrafo faz com que, de acordo com Troppmair (1985) o profissional da ciência geográfica não estude/perceba o meio físico apenas como um produto final, com um olhar único e isolado em si, mas como um meio integrado, interrelacionado e dinâmico em que todos os seres vivos, entre eles os seres humanos, desenvolvem todas as suas atividades cotidianas em busca da sobrevivência e organização das ações no território, como a da prática turística.

Evidencia-se, portanto, a necessidade em ordenar a prática do turismo, porém essa prática considera-se tardia no Brasil, já que apenas na década de 1940 surgem os primeiros ordenamentos públicos sobre o tema. Nesse momento o fenômeno turístico ainda era inexpressivo e não possuía o caráter de política pública, fator este que adquiriu somente a partir da primeira década do século XXI no âmbito da esfera federal brasileira.

Um dos vieses de controle e ordenamento é o segmento do ecoturismo, que: 
[...] é um componente importante para promover a sustentabilidade e conservação da natureza e grande parte das Unidades de Conservação (UCs) brasileiras têm grande potencial para receber as atividades ecoturísticas (RANGEL; SINAY, 2019, p.563).

O processo de planejamento turístico objetiva atender às necessidades dos indivíduos (sejam moradores locais ou os próprios turistas) e contribuir para o desenvolvimento das localidades, ocasionando uma melhoria na qualidade de vida generalizada, (ALMEIDA et al., 2007). Nesse sentido, fica claro que o devido planejamento de políticas públicas com foco no setor turístico decorre da urgente necessidade da mitigação dos problemas sociais, ambientais e culturais, haja vista que apesar de oferecer vantagem em alguns aspectos, pode também ser considerada uma atividade de risco caso exista sem um planejamento adequado (SANTOS; TEIXEIRA, 2009).

A dinamicidade e organização desse território turístico, como dito anteriormente, está traduzida objetivamente nas diversas manifestações econômicas, disputa por recursos naturais, e subjetivamente nas apropriações culturais, relações sociais, identidade territorial e nas diárias ações antropogênicas que constroem e modificam a sua paisagem.

\section{A organização do território turístico maranhense: as potencialidades turísticas do município de Morros (MA)}

Com fulcro na legislação vigente a respeito do tema, cada ente federado ficou com a responsabilidade de elaborar as suas respectivas regiões/divisões turísticas. Ou seja, cada Estado brasileiro fica incumbido de dispor de dispositivos normativos que versem sobre o ordenamento territorial e, também, a orientação das políticas do setor turístico com um caráter integralista através da coordenação e prospecção das práticas e subsídios para o incentivo da manutenção e desenvolvimento sustentável da prática supracitada.

O Maranhão é um dos estados da federação que possui um dos maiores potenciais turísticos do Brasil, haja vista que apresenta uma grande diversidade de atrativos naturais, históricos e culturais. Com base nisso, visando um efetivo planejamento público, o território maranhense fora dividido de acordo com características e potencialidades municipais agrupadas em forma de polos turísticos (FERREIRA, 2007).

Apesar da grande potencialidade, é o Estado do Maranhão é incipiente quanto ao poder exercido pelas legislações sob o prisma do planejamento e gestão dos recursos e das práticas turísticas em seus municípios que, em quase sua totalidade, iniciaram seus projetos sob o viés do planejamento urbano a partir das previsões e exigências de caráter constitucional e do próprio Estatuto da Cidade, por exemplo (SANTOS; GÂNDARA, 2016).

Essa divisão em que está submetido o território maranhense baseia-se em instrumento normativo denominado Plano Maior (entende-se: Plano de Desenvolvimento Integral do Turismo do Maranhão), cuja versão atual remonta a data de novembro do ano de 2011, totalizando cerca de 10 polos, conforme exposto no mapa a seguir: 


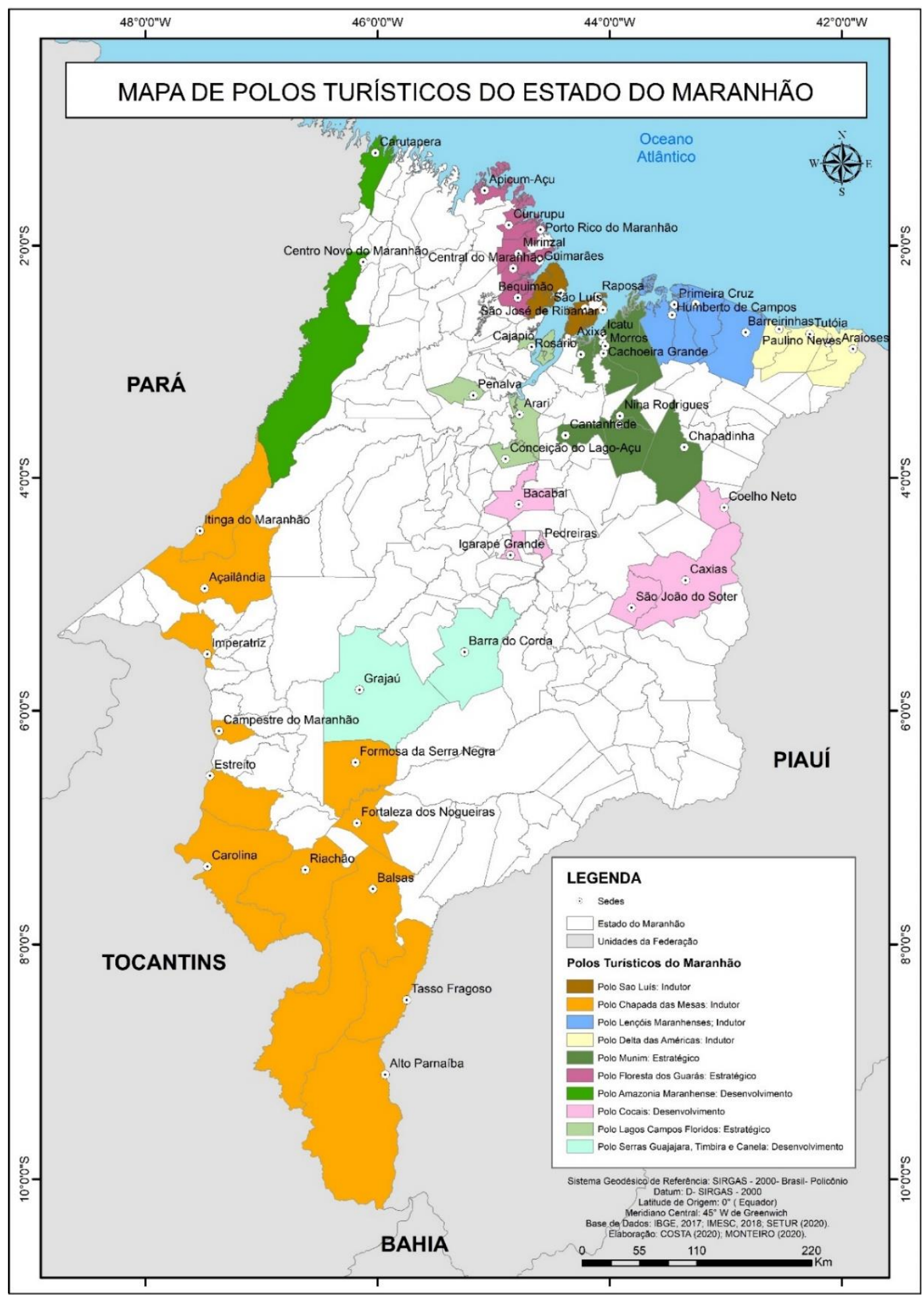

Mapa 1: Mapa de Polos Turísticos do Estado do Maranhão.

Map 1: Map of Touristic Areas in Maranhão State.

Fonte: Adaptado de Costa (2020); Monteiro (2020).

Source: Adapted from Costa (2020); Monteiro (2020).

A área do Polo Turístico do Munim, criada no ano de 2010, inserida dentro da Região de Planejamento do Baixo Munim, é compreendida por cerca de seis municípios, sendo eles: Axixá, Cachoeira Grande, Icatu, Morros, Presidente Juscelino e Rosário (MARANHÃO, 2012). 
A supracitada compartimentação turística do território maranhense está inserida na Área de Proteção Ambiental (APA) de Upaon-Açu/Miritiba/Alto Preguiças, devidamente instituída pelo Decreto-Lei de número 12.428/92. Ressalta-se que essa localidade foi recentemente incorporada à Região Metropolitana da Grande São Luís (RMGSL), composta atualmente por 13 municípios, responsável por expressivo fluxo econômico, social, cultural e de grande importância ambiental para o Estado.

A Região do Baixo Munim apresenta características ambientais substanciais como uma área de transição do Cerrado/Amazônia, bem como a presença de afluentes de águas cristalinas, corredeiras e pequenas cachoeiras ao longo dos rios Una, Arruda e Boqueirão. Além disso, essa parcela do território tem presenciado uma nova restruturação diante da diversificação de suas atividades econômicas, disponibilização de recursos naturais, potencial para a exploração mineral para fabricação de materiais da construção civil; valorização do território; estabelecimentos de indústria para exploração mineral; potencialidade produtiva de insumos agrícolas; grande potencialidade, exploração turística, sobretudo para o ecoturismo e o geoturismo, termos que serão abordados em um tópico posterior.

Dessa forma, é relevante destacar que os atores sociais e o turismo contemporâneo no Brasil têm se preocupado cada vez mais com as temáticas relacionadas à preservação do ambiente natural, bem como a sua sustentabilidade e a sua proteção, notadamente em virtude do agravamento das condições ambientais provocadas pelas ações antropogênicas e modelo econômico vigente.

Como já exposto, um dos municípios que compõem o chamado Polo Munim, é o município de Morros, banhado pelos rios Munim e Una considerados expoentes da beleza natural e potencial turístico da região (Mapa 2, próxima página), que com a presença de areia em seus leitos, formam diversos balneários frequentados para banho turísticos (MARANHÃO, 2012).

Nesse sentido, ressalta-se que dos seis municípios que compõe o Polo Munim, Morros é o que apresenta a atividade turística com um maior grau de desenvolvimento e expressividade. Isso significa dizer, portanto, que ocupa posição de destaque no cenário turístico maranhense, tendo em vista que possui grande potencial turístico ecológico (entende-se: turismo de aventura e ecoturismo) e cultural com a presença de praças e igrejas como a da Paróquia da Nossa Senhora Aparecida do Munim (Figura 1), por exemplo.

A sua constituição geográfica é composta de uma grande quantidade de morros, algo que caracteriza e dar nome à região, alémdisso a região também dispõe de uma significativa mata nativa, recoberta por formações vegetais distintas. Essa localidade está inclusa na bacia do Munim sendo banhada pelos rios Munim e seus diversos afluentes como: o rio Una, Mocambo, Axuí, entre outros 


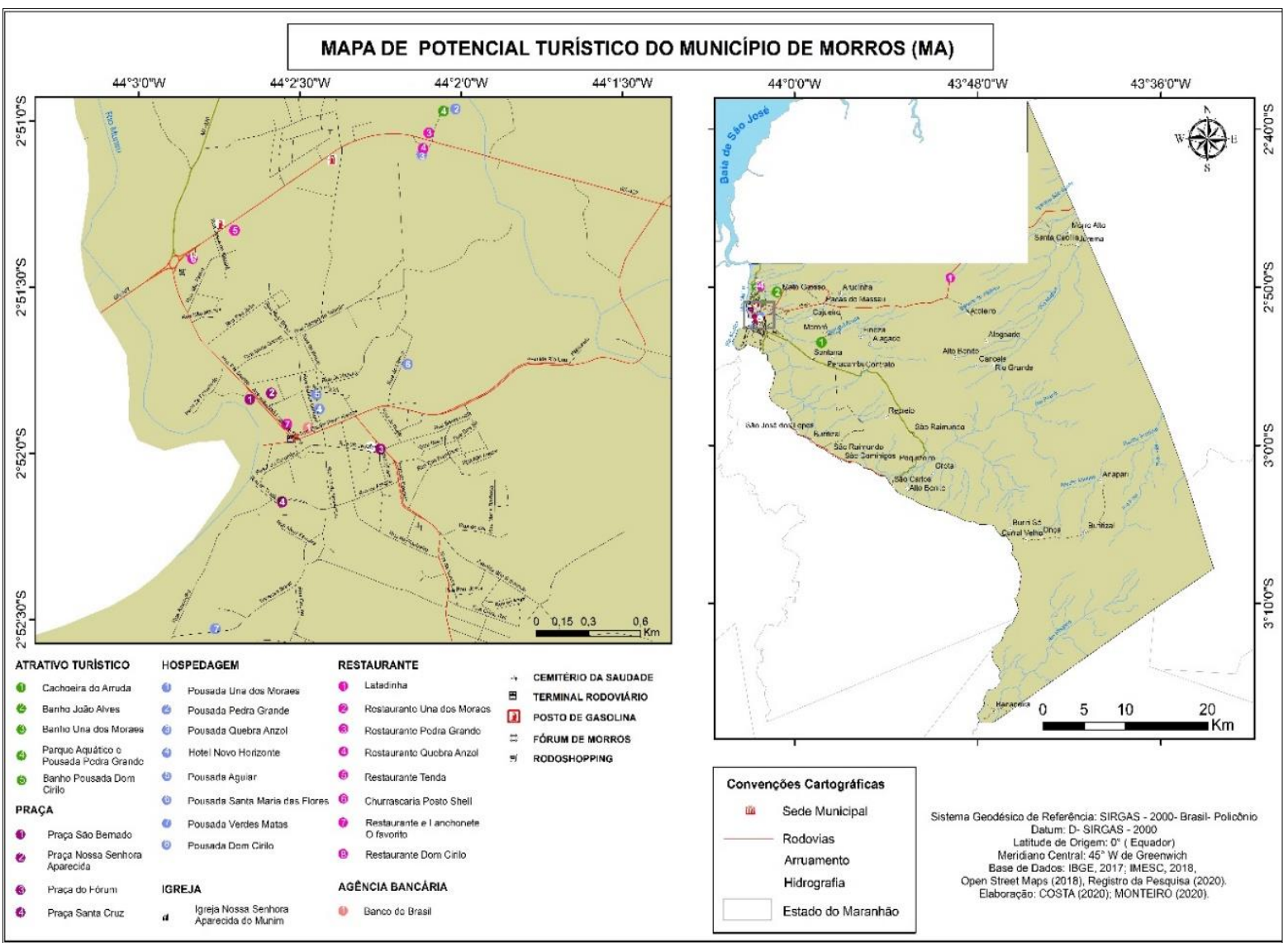

Mapa 2: Mapa de Potencial Turístico do Município de Morros (MA).

Map 2: Map of Touristic Potential Areas in the Municipality of Morros (MA).

Fonte: Adaptado de Costa (2020); Monteiro (2020).

Source: Adapted from Costa (2020); Monteiro (2020).

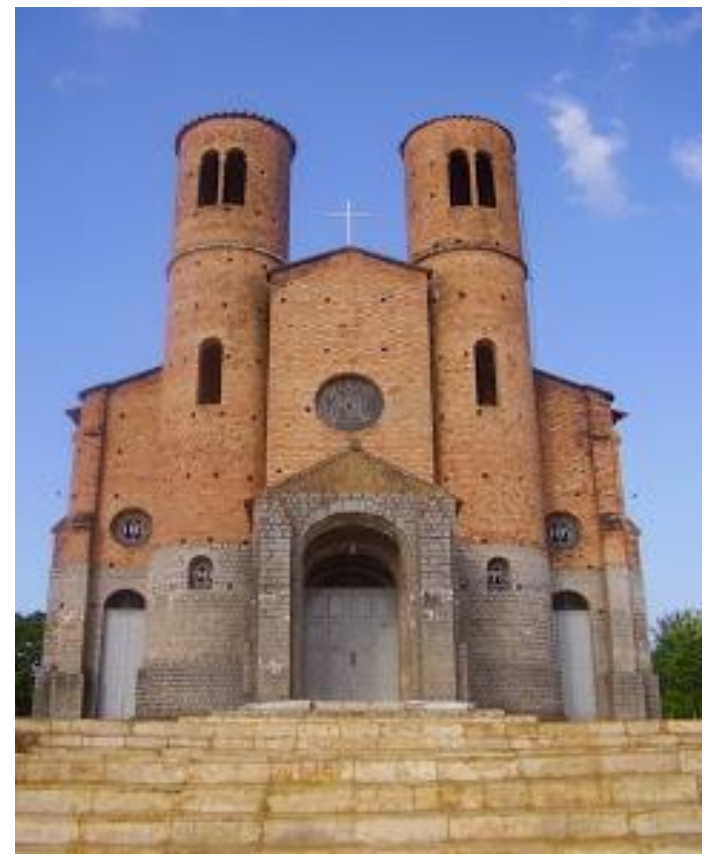

Figura 1: Paróquia da Nossa Senhora Aparecida do Munim.

Figure 1: Nossa senhora Aparecida Munim Church.

Fonte: Carlos (2010).

Source: Carlos (2020). 
A forte influência exercida pelas marés que penetram pela foz do rio Munim, faz com que ele seja propício para a prática da pesca tanto de água doce como de água salgada, além de apresentar uma navegabilidade em toda sua extensão no referido município, acrescentando assim mais um atrativo turístico.

Porém, a principal atração turística local é, sem dúvidas, o Rio Una, que possui um leito formado por vários trechos de rochas e pedras (Figura 2), bem como em suas margens que apresentam uma vegetação de mata densa com a presença de expressiva quantidade de juçarais (Euterpe edulis).

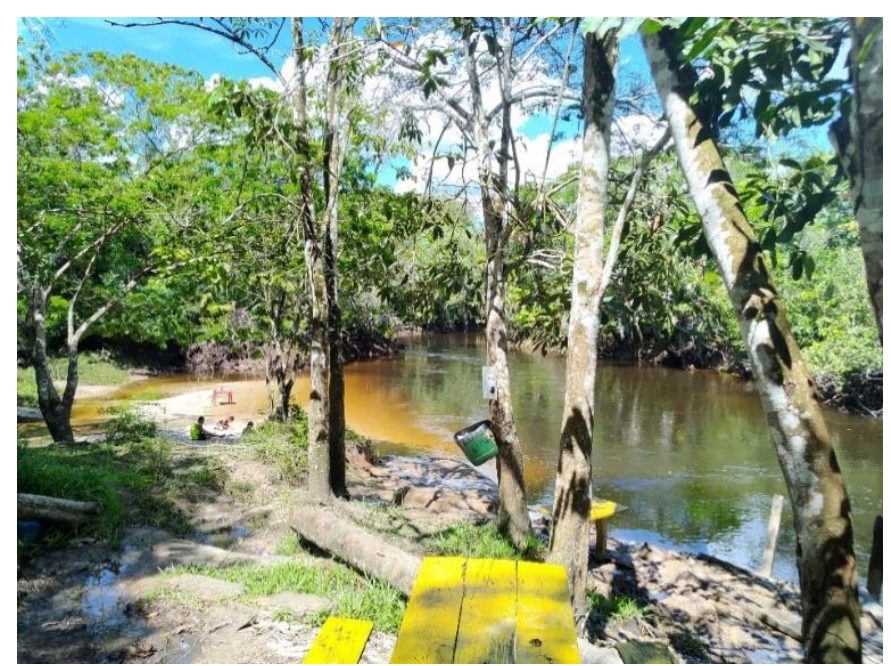

Figura 2: Leito do Rio Una no Município de Morros.

Figura 2: Uma River in the Morros Municipality.

Fonte: Costa (2020).

Source: Costa (2020).

Além disso, os visitantes podem apreciar passeios de barcos pequenos ou canoas que os possibilitarão conhecer outros balneários como: Balneário Una dos Paulinos, Balneário do Bom Gosto, Una do Mato Grosso, Una Grande, Una das pedras, Una das mulheres, Una dos escoteiros, Una dos Moraes, Una da Fazenda, Una dos Bois e a cachoeira do Arruda, com expressiva beleza cênica.

A cachoeira do Arruda (Figura 3), um dos principais potenciais turísticas da localidade por exemplo, encontra-se afastada da sede municipal de Morros e o acesso é realizado por meio de veículos automatizados e trilhas.
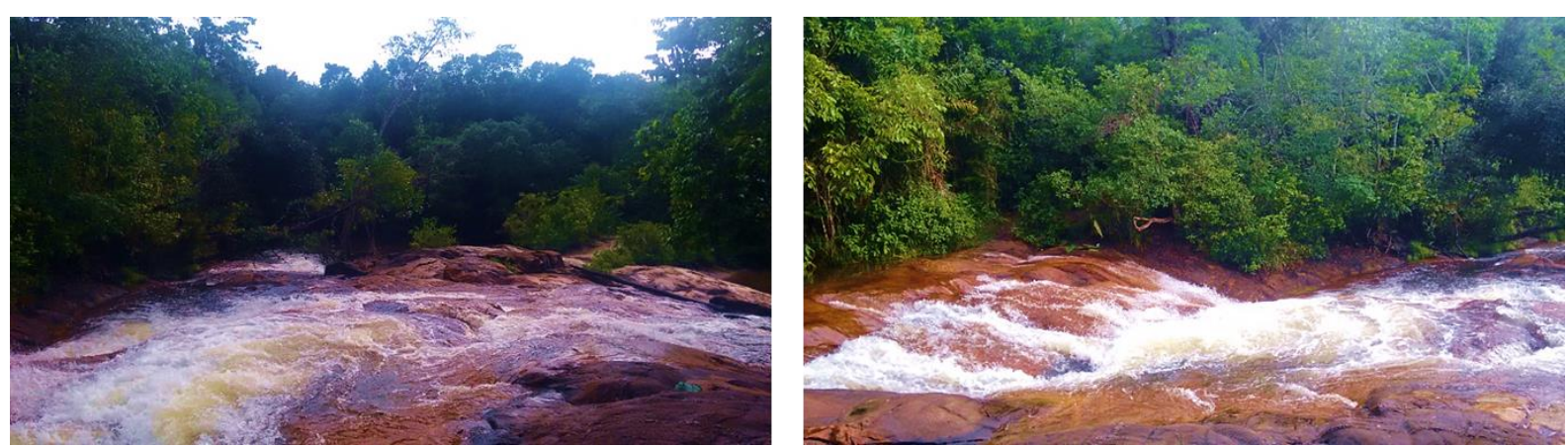

Figura 3: Cachoeira do Arruda em Morros.

Figure 3: Arruda Waterfall in Morros.

Fonte: Costa (2020).

Source: Costa (2020). 
O local é considerado um atrativo turístico, formado por uma pequena queda d'água que desagua e origina piscinas naturais de águas cristalinas e geladas, considerado um dos principais diferenciais oferecidos aos visitantes no município de Morros.

\section{Impactos causados às atividades/potencialidades turísticas no município de Morros no Maranhão}

O turismo é uma das ações antropogênicas que mais influência e transforma a construção, dinâmica e organização de um determinado território ao longo dos períodos históricos. Nesse sentido, é plena responsabilidade dos planejadores e gestores competentes do turismo a elaboração e proposição de políticas públicas substanciadas na mobilização e participação social e que se aproximem de um modelo mais embasado no desenvolvimento (CORIOLANO, 2003).

O planejamento com base nas políticas públicas deve ser percebido como um conjunto de decisões político-sociais e não apenas sobre a perspectiva técnica ou meramente administrativa. Esta gestão e ordenamento do território de Morros, conforme - Plano Maior, perpassa por segmentos como ecoturismo, e mais recentemente o geoturismo, que com ausência de instrumentos e incentivos públicos, dificulta a implementação destes, que poderiam difundir conceitos críticos e em rede sobre a preservação, conversação e maior caráter cognitivo na viagem (MEIRA; NASCIMENTO; SILVA, 2020).

A ausência de ferramentas institucionais de incentivo configura uma grande perda, especialmente, diante das potencialidades das diferentes regiões do país. $O$ fato também dificulta para o geoturismo atuar enquanto ferramenta de desenvolvimento em áreas economicamente deprimidas e distantes de grandes centros, bem como promover o seu potencial para a valorização ambiental e cultural local.

O pleno sucesso da implementação de uma política pública em determinada localidade, está diretamente relacionada à disponibilidade de informações corretas, participação popular em todos os processos de elaboração, transparência, discussões teóricas e metodológicas, visando buscar a solução dos conflitos que sejam aceitáveis a todos os participantes sociais, levando em conta, inclusive, às suas diferenças. (OLIVEIRA, 2006).

Portanto, o planejamento formata-se em um processo político-ideológico. Isso significa dizer que há a possibilidade da construção de planejamentos autoritários, com pouco comprometimento com o aspecto social, bem como aqueles que são considerados participativos, ou seja, que inclui os sujeitos sociais locais direta e indiretamente atingidos por esse planejamento (FRATUCCI; MOARES, 2020).

Nesse sentido os conjuntos de políticas públicas focalizadas às práticas do turismo visando a sustentabilidade e o desenvolvimento municipal, por exemplo, deve constituirse de um documento de caráter público, que aglutine o pensamento e as ações do poder público nas esferas local, estadual, regional ou nacional. Essa organização do setor turístico em uma determinada localidade deve valer-se de objetivos, metas, diretrizes e estratégias bem estudados e claramente definidos, haja vista que as políticas públicas de viés setorial são um marco normativo para o efetivo planejamento do setor, seja direcionados aos agentes públicos quanto para a iniciativa privada de maneira geral. 
$\mathrm{Na}$ localidade em que houver a prática do turismo, deve existir um planejamento turístico da região, pois na ausência ou carência de um, ocorrerá o crescimento não planejado da atividade que poderá acarretar expressivos problemas ambientais e sociais, como tem sido identificado no Município de Morros.

O desenvolvimento regional, é representado pelo cuidado com o desenvolvimento endógeno de determinado território, com a devida valorização das potencialidades locais no intuito implementar atividades de base local. Diante disso, Amaral Filho (1996) expõe o conceito de desenvolvimento endógeno da seguinte maneira:

Um processo de crescimento econômico que implica uma contínua ampliação da capacidade de agregação de valor sobre a produção, bem como da capacidade de absorção da região, cujo desdobramento é a retenção do excedente econômico gerado na economia local e/ou a atração de excedentes provenientes de outras regiões. Esse processo tem como resultado a ampliação do emprego, do produto e da renda do local ou da região (AMARAL FILHO, 1996, p. 37).

A ausência de um efetivo planejamento, gestão, controle e monitoramento turístico para o Polo Munim e, especificamente, voltado também para as potencialidades do município de morros tem acarretado cada vez mais problemas significativos para a localidade na última década.

A intensificação no processo de construção e ampliação da infraestrutura de residências, pousadas e bares em locais impróprios e em desconformidade com o Código Florestal, geralmente às margens do Rio Una, tem contribuído, sobremaneira, com a perda da vegetação nativa e assoreamento do leito do rio. Aliada ainda a essa situação, encontra-se a exponencial atividade turística, que não acontece de forma controlada e sustentável quanto a quantidade de pessoas frequentando diariamente e nem se preocupa com o usufruto ambientalmente correto das características naturais do local.

Outro problema existente é ocasionado pelo expressivo fluxo de visitantes atraídos pelos banhos que favorecem a degradação/modificação do leito dos rios e, também, pela grande quantidade de resíduos sólidos deixadas/esquecidas às margens sem a devida destinação.

O processo natural de erosão das margens dos rios causadas, principalmente, pela ação das águas e dos ventos, contribui para a exposição das raízes das vegetações ciliares na medida em que parte do solo foi levada pela força da correnteza. Essa grande quantidade de sedimentos retirados das margens acaba por acelerar o já avançado assoreamento do Una.

Além disso, o turismo de massa nos supracitados Balneários locais agride o meio natural de inúmeras maneiras como: a poluição hídrica (através do óleo e combustível das embarcações), poluição sonora (com a presença de carros de som), a inobservância dos limites da fauna e flora local, processo de assoreamento dos respectivos rios, por exemplo.

Essas diversas atividades turísticas e socais se intensificam durante os períodos de fins de semana e feriados, uma vez que, por apresentar relativa proximidade (cerca de 100 quilômetros) com a capital maranhense, São Luís, somadas aos baixos custos dos serviços, hospedagens e belezas naturais significantes, atraem um contingente de pessoas interessadas em um turismo com foco no natural. 
Como já exposto, a falta de efetivo comprometimento com a atividade turística por parte da gestão competente acaba por impedir o devido ordenamento territorial adequado. Michael Hall expõe, nesse sentido, que:

Embora o planejamento não seja uma panaceia para todos os males, quando totalmente voltado para processos ele pode minimizar impactos potencialmente negativos, maximizar retornos econômicos nos destinos e, dessa forma, estimular uma resposta mais positiva por parte da comunidade hospedeira em relação ao turismo no longo prazo (HALL, 2001, p. 29).

Nesse contexto, nas últimas décadas, fizeram-se com urgente necessidade, principalmente por parte do poder público, a valorização do conhecimento, dimensão e real situação da disponibilidade dos recursos naturais presentes sob seu domínio, haja vista que isso se torna um dos instrumentos fundamentais para o estabelecimento de critérios no que diz respeito ao chamado planejamento sustentável, provimento do manejo ecológico e integridade da biodiversidade e ecossistemas, visando também a garantia do desenvolvimento econômico e a minimização dos impactos ambientais e sociais.

O conflito de interesses surgidos desses procedimentos envolve diferentes percepções de desenvolvimento, da sustentabilidade e fragilidades socioambiental em distintas perspectivas escalares. O processo de modificação de um dado espaço em território turístico requer a readequação desse espaço à sua nova funcionalização e perspectiva. Esse referido processo pode significar a criação de um sistema de objetos que se aproxime e identifique ao sistema de ações advindo da demanda social do turismo no município.

\section{Os conceitos de Ecoturismo, Geoturismo e a aplicabilidade nas potencialidades turísticas para o desenvolvimento do turismo maranhense}

O fenômeno do turismo é umas das atividades sociais contemporâneas que mais se destaca e cresce em toda economia mundial, porém, para que haja sua efetiva compreensão, é necessário percebe-la não como uma atividade de componentes meramente isolados, mas sim, como uma prática composta por uma relação dialética dos mais diversos fatores econômicos, sociais, políticos, ambientais, culturais e institucionais, os quais evidenciam a necessidade de planejar o turismo a partir de um olhar sistêmico da sociedade e de sua relação com a natureza e geodiversidade.

A ausência de observância do caráter geral e multidisciplinar do turismo incorrerá em risco para a sustentabilidade da atividade e, por isso, o planejamento estratégico da atividade turística, impreterivelmente, deverá incluir a análise adequada dos fatores institucionais, culturais, sociais, políticos, econômicos e ambientais pertencentes à dinâmica local (HALL, 2000).

Sob essa perspectiva, destaca-se o conceito de ecoturismo trata-se de um viés turístico recente, que tem adquirido importância seja pela ótica econômica, social, cultural ou ambiental, pois como expõe Serrano (2000b), antes mesmo das definições dos termos e da comercialização de atividades relacionadas ao ecoturismo, já existiam algumas viagens focadas no próprio ambiente natural. Nesta perspectiva, Rangel e Sinay (2019, p. 
565) ressaltam que o ecoturismo "é uma alternativa econômica (ao turismo) de baixo impacto que, se bem planejada, ordenada, operada e monitorada, tem condições de contribuir de maneira valiosa para sustentabilidade regional de uma Unidade de Conservação".

Segundo Moreira (2010), a principal diferença entre o ecoturismo e o turismo convencional, é que o ecoturismo pode ser considerado uma segmentação do próprio turismo que propõe a prática de forma ambientalmente responsável, observando minuciosamente os critérios e princípios da sustentabilidade ambiental local.

Mediante a sua importância, o ecoturismo pode ser conceituado, segundo CeballosLascuráin (1987 apud PIRES, 1998, p. 79), como:

[...] viagem a áreas naturais que se encontram relativamente sem distúrbios ou contaminação com o objetivo específico de estudar, admirar e desfrutar a paisagem juntamente com suas plantas e animais silvestres, assim como qualquer manifestação cultural (passada ou presente) que ocorra nestas áreas.

Isso significa que a prática do ecoturismo pode ser percebida como uma alternativa para o desenvolvimento econômico e social de uma localidade, bem como, uma ferramenta de conservação já que proporciona receitas oriundas das taxas pagas pelos visitantes, significando assim, como exposto por Serrano (2000b) uma prática sustentável em um contexto insustentável, isto é, com base na lógica capitalista.

Além do exercício do ecoturismo supracitado, destaca-se também a valorização do conceito de geoturismo, nas últimas décadas, graças ao processo contínuo de segmentação de mercado, que se baseia na concepção da demanda ou também da oferta, em função de suas características particulares, com fulcro na denominação e concepção do já exposto turismo sustentável.

Nesse sentido a expressão "geoturismo" emerge como uma prática diretamente impregnada ao ecoturismo, mas possuindo um foco mais voltado ao aspecto físico do espaço ambiental, abiótico e, sobretudo, buscando alcançar outras dinâmicas impostas pela sustentabilidade que o próprio ecoturismo não conseguiu atingir através de suas práticas (LOBO et al., 2012).

Assim, o geoturismo apresenta-se como uma prática promissora do turismo, ao expor características específicas e essenciais à conservação da geodiversidade, em plena consonância com as diversas necessidades exigidas para o desenvolvimento econômico local e das populações que podem e devem ser envolvidas no processo (LOPES et al., 2011). Portanto, apresenta-se como uma atividade turística imprescindível na conservação e sustentabilidade da localidade, bem como fomentar ações de educação ambiental (DEGRANDI; FIGUEIRÓ, 2011; NASCIMENTO et al., 2007). E aliado ao ecoturismo, possuem:

[...] enorme potencial para ajudar a conservar o patrimônio natural e cultural, potencializando os ganhos financeiros das regiões próximas e dos próprios gestores, com a utilização de hotéis, restaurantes, esportes e opções ecoturísticas, entre outras atividades (RANGEL; SINAY, 2019, p. 566). 
A dimensão estratégica da prática do geoturismo é composta, portanto, pela interpretação pertinente da porção física da paisagem e 0 fomento à educação/conscientização ambiental que alcance o objetivo da conservação do patrimônio natural do local. Assim, a premissa do geoturismo contempla a geodiversidade, cujo cerne integra a diversidade geológica (rochas, minerais e fósseis), geomorfológica (formas de relevo) e pedológica (solos), além dos processos que lhes originaram (BÉTARD et al., 2011).

Diante disso, além dos termos citado nos parágrafos anteriores, para que exista o desenvolvimento e um caráter de sustentabilidade da prática turística nos territórios, é preciso a instauração de um processo de planejamento público eficaz, que considere dentre vários outros aspectos a avaliação da capacidade de carga dos territórios, percebendo de maneira estrutural os aspectos físicos, econômicos, sociais, culturais e ambientais, pois somente com base nesse conhecimento prévio é que se torna possível potencializar o lugar para que se torne de fato um produto turístico de qualidade.

Assim, com fulcro na potencialização no fornecimento da qualidade do turismo, principalmente em locais de carência da gestão e parâmetros legislativos, é imprescindível o processo de organização da disposição dos elementos que compõem a paisagem urbana, que fomentará assim o desenvolvimento e manutenção dos potenciais turísticos: "a ordenação turística é a busca conveniente dos meios existentes no espaço para o sucesso das propostas relativas às atividades turísticas" (CASTROGIOVANNI et al., 1999. p. 23). Ou seja, identificar uma ordem de prioridades e investimentos nas qualidades presentes no território, sejam naturais, sociais ou culturais, alavancam o turismo local e, principalmente, possibilitam uma qualidade de vida da própria população afetada por esse processo.

Seguindo o pressuposto do planejamento e ordenamento territorial, destacam-se as localidades que exploram o seu potencial turístico caracterizado pela criação de meios que justifiquem e mantenham a prática do turismo, com base nos seus elementos naturais, sociais ou culturais exponenciais, como os encontrados no município de Morros.

Entretanto, a realidade brasileira, sobretudo a maranhense, expõe que a maioria dos municípios não possuem um estudo sistematizado sobre a sua capacidade de carga aplicada aos seus potenciais turísticos onde a atividade já se encontra bastante consolidada e, na maioria das situações, em estado avançado de degradação ambiental.

Nos municípios em que o turismo está consolidado e consiste no principal elemento de renda e empregabilidade da maioria população (em que se inclui o município de Morros), a necessidade de listar os potenciais turísticos locais se faz urgente, principalmente com o intuito de mitigar as ações negativas, assim como a busca por potencializar as áreas positivas. Como mencionado a contemporaneidade baseia-se na tendência do turismo sustentável, possuindo a premissa da otimização das paisagens apropriadas pelas atividades humanas. 


\section{Considerações Finais}

Com base no exposto, sob o ponto de vista do processo de planejamento e da gestão dos territórios apropriados para a prática do turismo e suas vertentes, é primordial a elaboração de políticas públicas, constantemente atualizadas, direcionadas para o seu ordenamento. Esses dispositivos de caráter normativo devem ser pensados partir da conjunção dialógica entre as ações dos diferenciados agentes sociais que produzem aquela realidade turística, ressaltando que não podem ficar limitadas apenas às ações dos fatores de mercado relacionadas ao Estado, sob o risco de estarem contemplando exclusivamente a atividade econômica do turismo, mas esquecendo-se de todas as demais dimensões sociais que esse fenômeno pode abarcar.

Identificou-se que no polo Munim, mais especificamente o município de Morros é detentor de potencial turístico, com foco nos segmentos do ecoturismo e geoturismo, porém, as ações públicas previstas no planejamento estadual do turismo não foram implementadas com este viés, o que mantêm o território desconectado a práticas sustentáveis do turismo.

Deve-se, portanto, partir do princípio de que a atividade turística modifica e constroem o território por possuir grande complexidade, haja vista que as mais diversas variáveis influenciam os processos ao mesmo tempo que também são influenciadas, originando uma realidade de contexto social, econômico e cultural extremamente complexa que somente equipes multidisciplinares poderão contribuir eficazmente no planejar fenômeno.

É inegável que a prática do turismo de massa está em ascensão no município de Morros e, apresenta-se como uma alternativa palpável para o desenvolvimento da localidade, pois traz consigo geração de emprego e renda, investimento substanciais em infraestrutura que beneficiam não só o turista, mas também à comunidade local. Porém, apesar dos diversos potenciais turísticos do município, é preciso repensar a prática turística sobre o viés do desenvolvimento sustentável a partir do Ecoturismo e do Ecoturismo, visando a manutenção dos ambientes e impedindo a degradação da natureza por esse fenômeno e suas categorias alternativas emergentes no Polo Munim e no Estado do Maranhão.

\section{Refêrencias}

AMARAL FILHO, J. Desenvolvimento Regional Endógeno em um ambiente federalista. In: Planejamento e Políticas Públicas, №14, dez.1996 (IPEA).

ALMEIDA, Regina Araújo de. Et al. Geografia e Cartografia para o turismo. São Paulo: IPSIS, 2007.

BÉTARD, F.; PEULVAST, J-P. e MAGALHÃES, A. O. Biodiversité, géodiversité et enjeux de leur conservation dans les montagnes humides du Nordeste brésilien. Bulletin De l'Association de Géographes Français, v.88, n.1, p.17-26., mar. 2011.

CASTROGIOVANNI, A.C. Turismo e ordenação no espaço urbano. In: CASTROGIOVANNI, A.C.; GASTAL, S. (org). Turismo urbano: cidades, sites de excitação turística. Porto Alegre: Edição dos Autores, 1999.

CORIOLANO, L. N. M. T; LIMA, L. C. Turismo comunitário e responsabilidades socioambiental. 1 ed. Ceará: EDUECE, 2003. 
DEGRANDI, S. M.; FIGUEIRÓ, A. S. Patrimônio natural e geoconservação: a geodiversidade do município gaúcho de Caçapava do Sul. Anais do VIII Congresso Nacional de Ecoturismo e do IV Encontro Interdisciplinar de Ecoturismo em Unidades de Conservação. Revista Brasileira de Ecoturismo, São Paulo, v. 4, n. 4, p. 515, 2011.

FRAGELLI, C.; IRVING, M.A.; OLIVEIRA, E. Turismo: fenômeno complexus da contemporaneidade? Caderno Virtual de Turismo, v. 19, n. 3, 2019, p. 1-18.

HAESBAERT, R. Da desterritorialização à multiterritorialidade. Anais do X Encontro de Geógrafos da América Latina (São Paulo), 2005.

HAESBAERT, R. O mito da desterritorialização. Do "fim dos territórios" à multiterritorialidade (rio de Janeiro: Bertrand Brasil), 2004.

HALL, C. M. The integrated tourism planning process: dealing with interdependence. In: HALL, C. M. (Ed.). Tourism Planning Polices Processes and Relationships. England, Pearson Education Limited. 2000.

HALL, C. M. Planejamento turístico. Políticas, processos e relacionamentos (São Paulo: Contexto), 2001.

LAMBIN, E. F.; MEYFROIDT, P. Land use transitions: Socio-ecological feedback versus socio-economic change. Land use policy, v. 27, n. 2, p. 108-118, 2010.

LIMA, L.C. Reestruturação socioespacial: do espaõ banal ao espaço da racionalidade técnica. São Paulo: AnnaBlume, 2006.

LOBO, H. A. S.; MOREIRA, J. C. e FONSECA FILHO, R. E. Geoturismo e Conservação do Patrimônio Natural em áreas cársticas brasileiras. Anais do Seminário da Associação Nacional Pesquisa e Pós-Graduação em Turismo, 9., 2012, São Paulo-SP. 2012.

MARANHÃO. Instituto Maranhense de Estudos Socioeconômicos e Cartográficos. Situação Ambiental da Região do Baixo Munim. São Luís: IMESC, 2012.

MEIRA, S.A.; NASCIMENTO, M.A.L.; SILVA, E.V. Geoturismo e roteiros turísticos: propostas para o Parque Nacional de Ubajara, Ceará, Brasil. Revista GeoUERJ. n. 36, 2020, p. 1-24.

MOREIRA, J. C. Geoturismo: uma abordagem histórico-conceitual. Revista Pesquisas em Turismo e Paisagens Cársticas, Campinas-SP, v. 3, n. 1, p. 5-10, 2010.

MORIN, E. O método 3: o conhecimento do conhecimento. Porto Alegre: Sulina, 1999.

NEWSOME, D.; DOWNLING, R. Geoheritage and Geoturism. In: REYNARD, E.; BRILHA, J. (org.). Geoheritage: assessment, protection and management. Amsterdan: Elsevier, 2018. 450p. p. 305-321.

OLIVEIRA, J.A.P. Desafios do planejamento de políticas públicas: diferentes visões e práticas. Revista de Administração Pública, v.40, n.1, p. 273-288, mar./abr. 2006.

PIRES, P. S. A dimensão conceitual do ecoturismo. Turismo: visão e ação. Itajaí, v.1, n.1, p.7591, jan/jun, 1998.

RAFFESTIN, C. Por uma geografia do poder. (trad.) Maria Cecília França, São Paulo: Ática, 1993.

RANGEL, L.A.; SINAY, L. Ecoturismo como ferramenta para criação de Unidades de Conservação no estado do Rio de Janeiro. Revista Brasileira de Ecoturismo, São Paulo, v.12, n.4, ago/out., 2019, pp.563-580. 
RODRIGUES, A.B. Turismo e geografia: Reflexões teóricas e enfoques regionais. São Paulo: Hucitec, 1996.

SANTOS, M. espaço e método. São Paulo, Nobel, 1985.

SANTOS, M. A Natureza do Espaço. Técnica e Tempo. Razão e Emoção. São Paulo: HUCITEC, 1996.

SANTOS, S. R.; GÂNDARA, J. M. G. Destino turístico inteligente: construção de um modelo de avaliação com base em indicadores para planejamento, gestão e controle de destinos histórico-culturais patrimônio da humanidade, analisando o caso de São Luís (MA, Brasil). CULTUR: revista de Cultura e Turismo. Ano 10, n. 2, 2016, p. 69-79.

SANTOS, S.R.; TEIXEIRA, M.G.C. Análise do plano de desenvolvimento turístico do estado do Maranhão: potencialidades e entraves na gestão de pólo turístico. Revista Turismo Visão e Ação. v. 11, ํo 02. p. 218-241, 2009.

SAQUET, M.A. Abordagens e concepções de território. São Paulo: Expressão Popular, 2007.

SERRANO, C. O "produto" ecoturístico. In: ANSARAH, M. G. R. (Org.). Turismo: como aprender, como ensinar. São Paulo: SENAC, 2000b, p. 203-234.

SILVEIRA, M.L. América Latina: cidade, campo e turismo. CLACSO, Consejo Latinoamericano de Ciencias Sociales, São Paulo. Dezembro, 2010.

TRIGO, L. G. G. Turismo e qualidade: tendências contemporâneas. São Paulo: Papirus, 1998.

TROPPMAIR, H. Geografia Física ou Geografia Ambiental? Modelos de Geografia Integrada. Simpósio de Geografia Física Aplicada. Bol. de Geografia Teorética, v.15, n.29-30, p.63-69, Rio Claro, 1985.

VIEIRA, E.W.; FERREIRA, A.J.A.; SERRA, D.J.S. Turismo e território: planejamento turístico para o desenvolvimento sustentavel do Polo Munim, Maranhão. Revista da Casa da Geografia de Sobral. v. 18, extra 2, 2016.

Gabriel Macedo Monteiro: Universidade Estadual do Maranhão, São Luís, MA, Brasil.

E-mail: gabrielmacedo12@hotmail.com

Link para o currículo Lattes: http://lattes.cnpq.br/8110654629664147

Saulo Ribeiro dos Santos: Universidade Federal do Maranhão, São Luís, MA, Brasil.

E-mail: saulosantosma@uol.com.br

Link para o currículo Lattes: http://lattes.cnpq.br/6334574563260950

Data de submissão: 27 de agosto de 2021

Data de recebimento de correções: 25 de novembro de 2021

Data do aceite: 25 de novembro de 2021

Avaliado anonimamente 